\title{
URGENSI PENDIDKAN SEJARAH DI ERA MILENIAL
}

\author{
Ranti Nazmi \\ Email : ranti.nazmi29@gmail.com
}

\begin{abstract}
Abstrak
Urgensi pendidikan sejarah di era milenial ini sering mendapat sorotan tajam dari berbagai kalangan. Hal ini berkaitan dengan kebutuhan praktis di era milenial ini. Namun sejarah tetap diperlukan dalam kehidupan masyarakat global berkaitan dengan penanam nilai sejarah. Tujuan penelitian ini adalah untuk mendeskripsikan urgensi pendidikan sejarah di era milenial. Metode penelitian ini adalah studi literatur berdasarkan literatur-literatur sejarah terkini. Hasil penelitian ini adalah memahami sejarah dapat memperkokoh tentang kehidupan masa kini. Dengan kata lain, belajar dari masa lampau untuk masa kini.Sehubungan dengan itu, harus ada perubahan paradigma pembelajaran sejarah dari situasi linier hapalan ke arah pemahaman makna moral kesejarahan.Keadaan ini memerlukan profesi bermakna guru sejarah termasuk di dalamnya perangkat pembelajaran di sekolah dan lingkup pendidikan yang lebih luas.
\end{abstract}

Kata Kunci: Urgensi, pendidikan sejarah, era milenial

\section{Pendahuluan}

Sejak tahun 2000 Masehi hingga sekarang kita telah memasuki abad yang disebut dengan abad milenium dan generasi manusia yang lahir di era tersebut disebut dengan generasi milenial. Era millennial antara lain ditandai oleh adanya generasi yang memiliki ciri aktif berkolaborasi, dan terbiasa berfikir out of the box. Generasi millennial tidak mau lagi dikurung oleh suatu pandangan tertentu, melainkan ia akan terus menjelajah, membuka diri, berintegrasi dengan semua aliran, pemikiran, pandangan, gagasan dan sebagainya dalam rangka memperoleh jawaban atas problema kehidupan yang kompleks.

Kata milenium ini berasal dari bahasaInggris, yaitumillennium atau millennia yang berarti masaseribu tahun.Perkembangan teknologi yang pesat menjadi penanda hidup di era milenia dewasa ini, seperti digital technology, cloning,dan sebagainya. Wajar jika kemudian banyak yang beranggapan bahwa hanya orang-orang yang berkecimpung di bidang Ilmu Pengetahuan Alam (IPA) yang mampu beradaptasi dengan kondisi ini, sementara mereka yang berkecimpung di bidang Ilmu Pengetahuan Sosial (IPS) akan kesulitan untuk beradaptasi dalam era milenial, termasuk mereka yang focus dengan pendidikan sejarah. 
Tidak bisa dipungkiri bahwa pada era milenial ini, pembelajaran sejarah menghadapi berbagai problema, antara lain lemahnya penggunaan teori, miskinnya imajinasi, hingga acuan buku teks dan kurikulum yang state oriented, serta kecenderungan untuk tidak memperhatikan fenomena globalisasi berikut latar belakang historisnya.

Jika melihat dari sisi penggunaan teori, tidak salah jika ada yang mengatakan bahwa pendidikan sejarah sangat lemah dalam penggunaan teori, karena sejarah memang tidak mempunyai teori.Sejarah meminta bantuan teori-teoridari disiplin sosial lainnya dalam setiap kajiannya, seperti teori dalam ilmu sosiologi, antropologi, dan sebagainya. Melalui teoriteoritersebut kajian sejarah akan lebih kaya makna. Hanya kemampuan guru-gurusejarah yang dirasa kurang dalam menggunakanpendekatan interdisipliner untuk kajian sejarah.

Selain itu, pembelajaransejarah juga juga tidak disertai percikan imajinasi yang membuat tinjauan akanperistiwa masa lalu menjadi lebih hidup dan menarik. Faktanya adalah dalam proses pembelajaran sejarah, masih banyak guru menggunakanparadigma konvensional, yaitu 'guru menjelaskan dan muridmendengarkan'. Metode ini sangat membosankan.Ia kemudian tidak memberikan sentuhanemosional karena siswa merasa tidak terlibat aktif di dalam prosespembelajarannya. Jika hal ini dibiarkan terus akan berpotensi memunculkan generasi yang mengalami "amnesia (lupaatau melupakan) sejarah bangsa sendiri.Apalagi dalam era milenial saat ini, di mana pembelajaran sejarah sudah dianggap tidak lagi penting, maka akibat besar yang dapat ditimbulkan adalah munculnya generasi yang tidak lagi ingat dengan sejarah bangsa sendiri.Untuk itu, paradigm pendidikan sejarah dalam era milenial ini harus segera diubah dan segera ditemukan paradigm baru yang cocok untuk menciptakan generasi muda yang selalu ingat dengan sejarah.

\section{Metodologi}

Dari dulu stigma yang melekat pada pembelajaran sejarah adalah bahwa pendidikan sejarah identik dengan hafalan.Selain itu, guru sejarah selalu diidentikkan dengan mengajar menggunakan pola konvensional, yaitu guru hanya berceramah dalam menjelaskan materi, dan siswa hanya mendengarkan.

Mengubah paradigma yang dianut oleh seorang guru dari paradigm konvensional ke paradigma konstruktif, bukan sesuatu hal yang mudah.Hal inidisebabkan karena kebanyakan 
guru sudah terbiasa dengan paradigm konvensional, dan mereka sendiripun pada waktu masih menjadi siswa sudahterbiasa dengan paradigma tersebut.Sungguh-sungguh diperlukan kemauandan tekad yang kuat untuk bisa mengubah paradigma tersebut secara nyata.

Schiffer dan Fosnot (1993) menguraikan proses jatuh bangun dari beberapaguru yang berusaha sungguh-sungguh untuk menggunakan paradigm konstruktivis, sekalipun mereka sendiri sebelumnya sudah sangat terbiasadengan paradigma konvensional. Dengan usaha yang keras, usaha para gurutersebut akhirnya berhasil mengubah paradigma yang mereka gunakan, danperubahan paradigma tersebut memberikan manfaat yang positif bagi para siswamereka, karena dengan penggunaan paradigma yang kedua tersebut, para siswamenjadi terbiasa mengeksplorasi secara aktif dan konstruktif konsep-konsep,prinsip-prinsip, prosedur-prosedur, dan soal-soal sejarah (termasuk soal-soalyang non rutin), sehingga mereka merasa bahwa sejarah adalah 'milik' mereka,karena liku-likunya telah biasa mereka telusuri.

Lebih jauh, hal tersebutmenambah rasa percaya diri mereka dalam menghadapi materimateri sejarahyang baru dan soal-soal yang sebelumnya belum pernah mereka jumpai.Hal inijuga sangat membantu mereka pada waktu mereka menjumpai masalah-masalahdalam kehidupan mereka sehari-sehari; sehingga secara umum, kemampuanmereka dalam memecahkan masalah kesejarahan meningkat. Kemampuanmemecahkan masalah ini akan sangat berguna pula dalam bidang-bidang dimana mereka nanti akan berkarya.

Belajar sejarah berarti peserta didik mampu berpikir kritis dan mampumengkaji setiap perubahan di lingkungannya, serta memiliki kesadaran akanperubahan dan nilai-nilai yang terkandung dalam setiap peristiwa sejarah.Pembelajaran sejarah yang baik adalah pembelajaran yang mampumenumbuhkan kemampuan siswa melakukan konstruksi kondisi masa sekarangdengan mengkaitkan atau melihat masa masa lalu yang menjadi basis topic pembelajaran sejarah.Kemampuan melakukan konstruksi ini harusdikemukakan secara kuat agar pembelajaran tidak terjerumus dalampembelajaran yang bersifat konservatif.Kontekstualitas sejarah harus kuatmengemuka dan berbasis pada pengalaman pribadi para siswa. Apalagi sejarahtidak akan terlepas dari konsep waktu, kontinyuitas dan perubahan.

Mengutip pendapat Fernand Braudel (Lechte, 2001) memahami sejarahdari sudut waktu.Menurutnya dalam memahami sejarah ada tiga kerangkawaktu, event history (short 
term/jangka pendek), conjucture (mid term/jangkamenengah) dan longue duree (long term/jangka panjang).Sejarah pada satutempat dan komunitas terkait dengan ketiga konsep waktu tersebut.Selain itudari sudut ruang, Braudel menambahkan satu lagi, yaitu ekonomi dunia di manaini merupakan unit analisis makro terkait dengan perkembangan pertukaranbarang dan jasa. Jika dikaitkan dengan waktu kalender,event historyberlangsung antara beberapa minggu, musim sampai beberapa tahun.Conjungture berlangsung sekitar 10 - 50 tahun sedangkan longue dureeberlangsung lebih lama, bisa sampai beberapa abad.

Perubahan yang mempengaruhi sejarah dalam jangka waktu yang lama,dicontohkan oleh Braudel yaitu mengenai perubahan musim atau iklim.Perubahan jangka menengah, misalnya yang terkait bidang ekonomi sepertiperubahan-perubahan harga, pertumbuhan populasi dan hasil-hasil produksi.Perubahan-perubahan ini bisa dipengaruhi oleh keadaan-keadaan sepuluh,duapuluh, lima puluh tahun yang lalu. Event history atau jangka pendekdigambarkan oleh Braudel seperti pada awal tulisan ini.Seperti cahaya kunangkunang,bersinar singkat dan lemah, tetapi cukup melepaskan cahaya untukmenyinari dataran kecil di bawahnya.Pada event history ini Braudel member tekanan pada perang, politik dan diplomasi.

Pembedaan ketiga konsep waktu ini, evant history, conjucture dan longueduree tidak merupakan pembedaan yang hirarkis, satu lebih penting dari yanglain. Masing-masing berperan dan mempunyai fungsi sendiri-sendiri, dan ketikatiga konsep waktu itu ditambah dengan unit analisis makro, ekonomi dunia,menurut Braudel keempatnya tersebut akan memberikan sudut pandang kitamengenai total history.Apabila pemikiran Fernand Braudel tersebut diterapkan dalampembelajaran sejarah, maka perlu adanya perubahan paradigma pembelajaranagar aktualitas akibat adanya perubahan dalam konsep waktu dapat dipahamidan disadari oleh para siswa.

Beberapa faktor di atas diangkat dalam makalah singkat ini, yaituperubahan pembelajaran sejarah dari pola lama menjadi pembelajaran sejarahdengan paradigma baru.Paradigma ini adalah pendekatan pembelajaran sejarahyang kontekstual berbasis konstruktivisme dengan memperhatikanperkembangan kekinian yang semakin global.

\section{Urgensi Pendidikan Sejarah di Era Milenial}


Seiring dengan perkembangan zaman hingga memasuki era milenial dewasa ini, yang menuntut pergeseran ke arah kebutuhan yang bersifat bendawi dan diikuti dengan adanya pergeseran budaya insani, mata pelajaran sejarah menjadi kurang popular di masyarakat, khususnya di kalangan generasi muda. Sikap demikian paling tidak akan menyebabkan pemahaman keliru sebagian guru sejarah ataupun siswa tentang makna pengajaran sejarah di sekolah. Lebih-lebih lagi apabila kenyataan ini dikaitkan dengan dinamika ilmu eksakta.Materi sejarah hanya dilihat sebagai materi hapalan karena berisi muatan materi yang membahas masalah bunuh membunuh, berebut kekuasaan antar penguasa, ganti bergantinya raja (Kumalasari, 2007).Hapalan peristiwa dari tahun ke tahun, dan anggapan miring atau stigma negative lainnya tentang pembelajaran sejarah di sekolah.Akibatnya, konsep moral yang sebenarnya terkandung dalam materi sejarah belum dapat disajikan secara bermakna seirama dengan kepentingan pendidikan moral siswa.

Kondisi di atas tentu saja sangat meresahkan.Oleh karena itu, di era milenial sekarang ini, pembelajaran sejarah harus kembali digalakkan, agar tidak dianggap remeh dan dipandang sebelah mata.Pembelajaran sejarah harus dianggap sebagai pembelajaran yang penting untuk terus mengingatkan kepada generasi muda mengenai makna dari mengingat sejarah itu sendiri.

Pembelajaran sejarah di lingkup pendidikan memiliki maknayang sangat penting bagi wujud dankeberlanjutan suatu bangsa.Sekait denganhal tersebut Wiriaatmadja (2002:55)menjelaskan bahwa sejarah sebagaibagian dari pengajaran anak manusiausianya sudah cukup tua, jauh lebih tuadari saat untuk pertama kali sejarahdituliskan.Sampai saat ini sejarah dimaknaisebagai peristiwa yang pernahberlangsung, kisah yang pernah terjadidan ilmu yang mempelajari peristiwaitu sehingga menghasilkan kisah sejarahyang dapat digunakan sebagai salahsatu sumber belajar bagi umat manusiadalam meniti kehidupan.

Alasan orang mempelajari sejarah di setiapnegara adalah (Moedjanto dalam Atmadi danSetianingsih, 2000:44):

1. Alasan intelektual yang berawal darikeinginan manusia untuk mengetahuimasa lalu peradaban mereka.

2. Dorongan eksistensial, yaitu adanyaamnesia untuk menanyakan tentangasal- usulnya. 
3. Doronganlegitimasi karena ingin memperolehpengabsahan atas kedudukannya.

Ketigadorongan inilah yang telah membuktikanbahwa bagaimanapun manusiaselalu mempunyai keinginan untukmencari akar jati dirinya sendiri,berikut legitimasi pemenuhan statussosial dalam kehidupan bersama.

Di samping itu, manfaat besar mempelajari sejarahantara lain menjadikan sejarah sebagaisalah satu cermin untuk mengarahkanperkembangan di masa datang. Sejakzaman Yunani dikatakan bahwa historiavitae magistra, ini bermakna sejarahadalah guru kehidupan (Haikal,1982:38-42). Tindakan dan perbuatan manusiamasa kini hanya dapat dijelaskan dandimengerti dengan menggunakan referensimasa lampaunya dan sejarah akanmembantu menjembatani rentanganwaktu itu. Tanpa sejarah, masa lampauhanya akan merupakan bahan pemuasperhatian sekilas dan praktis manusia.

Didasarkanpada pengetahuan masa lampau tersebutapabila dikaji dengan perspektifyang benar akan mampu membekaliskill performance manusia dalam menghadapisituasi yang sama pada masakini, memberikan pengertian dan pemahaman,menstimulasi imajinasi sertamembentuk kerangka berpikir yangmantap menuju pribadi bermakna,smart, dalam kehidupan. Untuk itu,Wiriaatmadja (1992:57) menegaskan perlunyapengajaran sejarah sebagai persiapanpendewasaan generasi muda dalammenjawab aneka tantangan masa depannya, khususnya di era milenial.

Di samping itu, pemberian materisejarah pada setiap jenjang pendidikantersebut juga merupakan sarana pewarisanbudaya (cultural transmission) dalamrangka proses sosialisasi dan enkulturasiuntuk mewujudkan penumbuhanjati diri generasi penerus. Dengankata lain dapat dinyatakan bahwapengajaran sejarah merupakan sumbernilai dan moral preceps yang mengikatperilaku pribadi dan kelompok sehinggaintegritas masyarakat serba terjaminkelangsungannya.

Berdasarkan uraian di atas dapat dikatakan bahwa pengajaran sejarah tetap diperlukan demi masa depan, khususnya generasi milenial. Hal ini diperkuat dengan anggapan bahwa masa lampau tetap merupakan guru yang paling baik dalam memperoleh kesuksesan di masa yang akan datang. Sejalan dengan sajian Moh. Iqbal, Van der Meulen (Widja: 2002) mengatakan bahwa sejarah cukup mampu membangkitkan keinsafan wujud manusia melalui gerakan 329 | Seminar Nasional Sejarah ke 4 Jurusan Pendidikan Sejarah Universitas Negeri Padang 
bermakna berupa peralihan dari masa lalu ke masa depan. Pengajaran sejarah mampu menyambung serba keunggulan di masa lampau dengan serba keunggulan yang lebih bermakna di masa depan yang semakin menantang. Dengan wawasan kesejarahan seperti ini, manusia bisa menerima aneka perubahan dan perkembangan di bidang apapun termasuk ilmu dan teknologi sebagai keharusan, sekaligus kewajaran, dalam perjuangan menuju peningkatan kualitas hidupnya.

Seirama dengan hal ini, pendidikan sejarah harus memiliki ciri seperti:

1. Menekankan pada sejarah global, bukan hanya nasional ataupun lokal;

2. Mengembangkan kepekaan moral untuk meningkatkan kesetiakawanan umat manusia;

3. Mampu mempersiapkan generasi baru tentang keyakinan yang berhubungan dengan bagaimana mensiasati kehidupan masa depan berdasarkan beragam pengalaman masa lampau yang dimilikinya (Issawi: 1962).

Dengan memperhatikan tiga hal tersebut, sebagaimana dikatakan oleh Toffler (Widja, 2000) bahwa pengajaran sejarah masih tetap bermakna di era milenial, dengan tekanan bermakna pada era milenial dengan segala keruwetannya.Bagaimanapun juga kehidupan masyarakat modern tetap memerlukan belajar sejarah, khususnya makna kesadaran sejarah seperti terwujud dalam perilaku bermakna dalam dinamika kehidupan sehari-hari.Untuk mencapai tujuan ini, penekanan pengajaran sejarah sebaiknya pada konsep makna sejarah yang berorientasi pada penanaman nilai yang dinamis, progresif, serta merangsang siswa untuk mengamalkan nilai-nilai masa lampau hingga menjadi kekuatan dan motivasi dalam menghadapi tantangan di era milenial. Pendidikan sejarah ini bukan menjejali siswa pada serba kegemilangan dan kebanggaan masa lampau yang dikhawatirkan melahirkan sikap chauvinis, sifat yang mengagungkan kebangsaannya tanpa mau melihat bangsa lain sebagai bagian dari kehidupan pada saat ini.

\section{Simpulan}

Dalam kenyataannya pembelajaran sejarah sering mendapat sorotan tajam dari berbagai kalangan, lebih-lebih apabila dikaitkan dengan kebutuhan praktis di era milenial.Namun demikian, sejarah tetap diperlukan dalam kehidupan masyarakat global kaitannya dengan

penanaman nilai sadar sejarah untuk menumbuhkan kemampuan intelektual yang kritis dan 330 | Seminar Nasional Sejarah ke 4 Jurusan Pendidikan Sejarah Universitas Negeri Padang 
tajam dalam menghadapi situasi yang terus berubah ini.Pemahaman sejarah diyakini dapat memperkokoh tentang kehidupan masa kini. Dengan kata lain, belajar dari masa lampau untuk masa kini.

Sehubungan dengan itu, harus ada perubahan paradigma pembelajaran sejarah dari situasi linier hapalan ke arah pemahaman makna moral kesejarahan.Keadaan ini memerlukan profesi bermakna guru sejarah termasuk di dalamnya perangkat pembelajaran di sekolah dan lingkup pendidikan yang lebih luas.

\section{DAFTAR PUSTAKA}

Atmadi, A dan Y. Setianigsih.2000.Transformasi Pendidikan MemasukiMillineum Ketiga. Yogyakarta: Kanisius.

Haikal, Husain. 1982. "Historiografi Yunanidan Romawi”, Informasi, No. 1,Th XII.

Issawi, Charles. "An Arab Philosophyof History" alih bahasa A. MuktiAli, 1962, Filsafat Islam tentangSedjarah, Djakarta: Tintamas

Kumalasari, Dyah. 2007. ’RadikalisasiMasyarakat Surakarta”. Dimensia,Vol I, No. 2.

Lechte, J. 2001. “50 Filsuf Kontemporer.Dari Strukturalisme sampai Postmodernitas”. Yogyakarta: Penerbit Kanisius

Schifter, D. and Fosnot, CT. (1993).Reconstruction Mathematics Education. Teacher's College, Columbia University.

Widja, I Gde. 2002. Menuju Wajah BaruPendidikan Sejarah. Yogyakarta:Lapera Pustaka Utama.

Wiriaatmadja, Rochiati. 1992. "PerananPengajaran Sejarah Nasional Indonesiadalam PembentukanIdentitas Nasional: Upaya Peralihannilai-Nilai Integ-ralistik dalamProses Sosialisasi dan EnkulturasBerbangsa di KalanganSiswa SMAK I BPK PenaburBandung“. Disertasi.PascasarjanaPIPS IKIP Bandung.

Wiriaatmadja, Rochiati. 2002. PendidikanSejarah di Indonesia: Perspektif Lokal,Nasional dan Global. Bandung:Historia Utama Press. 